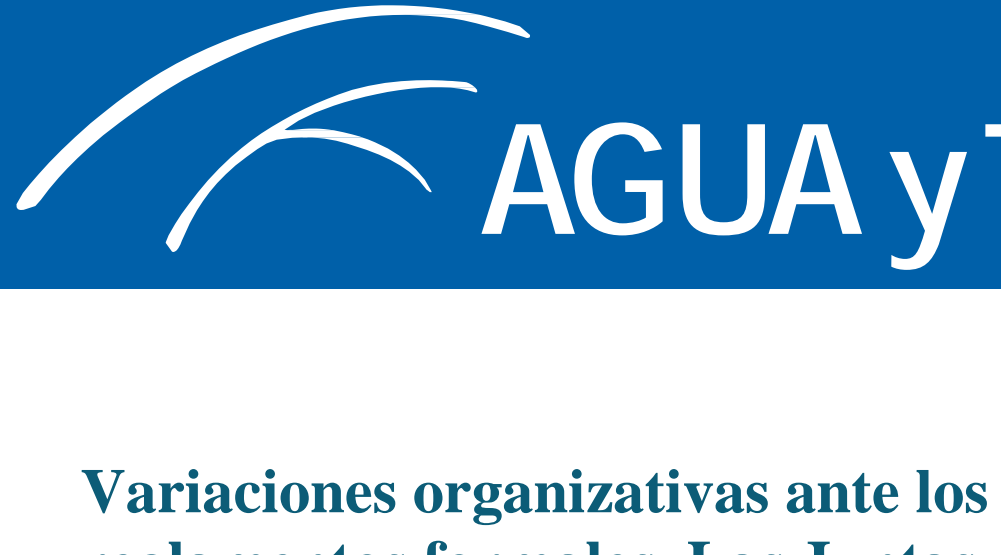 reglamentos formales. Las Juntas de Aguas en México 1920-1980
}

\section{water and landscape} ERRITORIO

\section{Organizational variations to formal regulations. The Water`s Council in México 1920-1980}

\author{
Acela Montes de Oca Hernández \\ Universidad Autónoma del Estado de México \\ Toluca de Lerdo, México \\ acela_cicsyh@yahoo.com.mx
}

\begin{abstract}
Resumen - En México, la reforma agraria alteró convenios de distribución y asignación de agua de ríos, arroyos y/o manantiales, proceso de cambio que se prolongó hasta el año de 1980. Sin embargo, no se ha explorado y analizado a las organizaciones preexistentes frente a nuevas formas de regular los usos colectivos del agua. La pregunta es ¿Cuál fue la relación entre reglamentos formales y la emergencia de Juntas de Aguas en el Estado de México? El objetivo es, identificar los espacios territoriales de las Juntas de Agua y examinar las respuestas sociales ante los reglamentos oficiales. El método de estudio es reflexivo-analítico de carácter cualitativo sustentado en documentos de archivo. La persistencia de las Juntas de Aguas permite atestiguar que, la intervención federal no logró atender funciones operativas y/o administrativas para controlar diversas corrientes, delegadas casi en su totalidad a las organizaciones locales.
\end{abstract}

\begin{abstract}
In Mexico, agrarian reform altered agreements for the distribution and allocation of water of rivers, streams and/or springs, a process of change that lasted until 1980. However, pre-existing organizations have not been explored and analyzed in the form of new ways of regulating collective water uses. The question is: what was the relationship between formal regulations and the emergence of Water`s Council in the State of Mexico? The objective is to identify the territorial spaces of Water's Council and examine social responses to official regulations. The method of study is qualitative-reflexive-analytical based on archival documents. The persistence of the Water's Council witness that, the federal intervention failed to attend operative and/or administrative functions to control diverse currents, delegated almost totally to the local organizations.
\end{abstract}

Palabras clave: Conflicto, Disputa, Juntas de aguas, Normatividad local, Reglamentos Keywords: Conflict, Dispute, Water's council, Local regulations, Regulations 


\section{INTRODUCCIÓN}

Las instituciones del regadío en países como la India, Egipto, China, México, Estados Unidos, Francia, España y Perú se han constituido con personal que posee conocimientos ingenieriles, además de habilidades políticas y socioculturales ${ }^{1}$. Las mismas investigaciones han resaltado las condiciones en que los usuarios han sido capaces de regular sistemas de riegos de diversos tamaños. En México, a partir del siglo XX, el tema del agua está entrelazado con el de la propiedad de la tierra. Es importante relacionar los recursos hídricos con la política agraria en el sentido de la redistribución y la emergencia de nuevos actores del campo rural, aclarando que el trabajo es restrictivo para disertar sobre la reforma agraria, sin embargo, nos permite vincular el manejo de agua con las nuevas formas de propiedad de la tierra.

Con la promulgación de la Ley Agraria de 1915 se atendió como tema prioritario la redistribución de la tierra, lo que significó poca atención al agua o esta fue considerada como parte de la tierra. Por otra parte, el Estado inició el fortalecimiento de sus instituciones poniendo especial atención a la producción agrícola y apostando por la construcción de obra hidráulica. El problema residió en la transformación de los derechos de propiedad de tierra, pues a la propiedad privada, estatal y comunitaria se adhirió la propiedad ejidal, estas habrían de contender administrativa y operativamente por el control hídrico ${ }^{2}$.

Años más tarde, para regular los diversos usos hídricos y desde lo perceptible en la Constitución Política de 1917, específicamente en el artículo 27, la federación, que desde 1888 buscaba fortalecerse, fue la única facultada para concesionar, controlar, proyectar, construir y reglamentar el uso y aprovechamiento del agua; aunque a la par discurrían gestores municipales, estatales, empresariales, comunitarios e individuales. En este contexto surge un principio normativo de dotación o restitución de tierras. Aquellos pueblos que mostraron pruebas fehacientes (presentación de documentos originales) que, durante la colonia, sufrieron despojo de sus tierras, éstas les fueron restituidas; caso contrario, recibieron dotación. En ambos temas la resolución era larga, los solicitantes debieron esperar de uno hasta sesenta años ${ }^{3}$.

Por su parte, los pueblos que carecieran de tierras de riego podían solicitar dotación de aguas, el caso de terrenos con riego se solicitaba dotación por accesión ${ }^{4} 5$. Estos cambios organizativos respecto a la nueva división del territorio afectaron no solo derechos de uso anteriores a la reforma agraria, también cuadros de distribución. No es menester de este trabajo referir a las ordenanzas anteriores a 1920, pero sí indicar que diversas investigaciones han dado a conocer su continuidad antes y

\footnotetext{
1 Stone, 1984, 105-129. Boelens, 2003. Palerm y Martínez, 2009, 15. Glick, 2010.

2 Mendieta, 1978. Castañeda, 2005. Aboites, 2004. Valladares de la Cruz, 2003. Aboites y Estrada, 2004. Escobar et al. 2009. Palerm y Martínez, 2013.

${ }^{3}$ Ley de dotaciones y restituciones de tierras y aguas. Reglamentaria de artículo 27 de la Constitución Mexicana de 1917.

${ }^{4}$ Tamayo (1956) indica que debería publicarse en el Diario Oficial de la Federación.

5 Para referencias de casos de despojo de agua remitirse a Tortolero, 2008. Torregrosa, 2009. Castañeda, 2005. Sandré, 2008.
}

después de que al personal del Estado de México se le ocurriera integrarlas $^{6}$.

Consideremos que, hasta antes de la supuesta fortaleza de la federación ${ }^{7}$ en materia de agua, el ayuntamiento, empresario, comunidad y particulares al considerar las aguas de un río, arroyo y/o manantial como "sus aguas", eran ellos quienes establecían las ordenanzas y en todo caso determinaban sus usos y costumbres, bien como individuos o colectividades. De manera que, "cada ciudad, hacienda y comunidad tenía sus autoridades, lo que no había, en todo caso, era una institución la cual los englobase" 8 .

A pesar de ello, en algunos espacios del territorio de México se carece de estudios que mencionen a las instituciones sociales encargadas de emitir y aplicar los reglamentos de agua del siglo XX. Por lo anterior, en el caso del Estado de México tratamos de exponer los actores e instituciones relacionadas con la distribución del agua durante el reparto agrario. De manera que es significativo en el tema de reparto de tierra los reglamentos de agua, sin embargo, las adaptaciones sufridas son la antesala que permite entender las tendencias organizativas tradicionales frente a la influencia institucionalizada.

El desarrollo del artículo esta desglosado en cuatro apartados: el primero refiere al contexto legal y social de los reglamentos de agua durante el reparto agrario; el segundo explica las Juntas de Agua como organizaciones locales, su estructura y funciones; el tercero refiere a los diseños organizativos propios del accionar colectivo; y el cuarto es una mirada a las transformaciones que enfrentaron estas organizaciones.

\section{MetodologíA}

Comprender desde la perspectiva social e histórica el comportamiento organizativo de la mixtura entre añejas y nuevas organizaciones; esto nos dirige en utilizar el método cualitativo, la unidad de análisis son las Juntas de Aguas, organizaciones electas por su notoria presencia y remembranza en documentos del siglo XX, así como su aún existencia en municipios del sur del estado para el 2016.

Para obtener datos respecto a su estructura y funcionamiento acudimos a tres archivos: Archivo Histórico del Agua (en adelante AHA), Archivo del Registro Agrario Nacional (en adelante ARAN) y Archivo Histórico del Estado de México (en adelante AHEM), además de la consulta del Diario Oficial de la Federación (en adelante DOF). Del AHA se consultaron los fondos documentales de: Aprovechamientos Superficiales (en adelante AS), Aguas Nacionales (en adelante AN) y Consultivo Técnico (en adelante CT); respecto al ARAN el grupo documental consultado fue Dotación y Accesión de Aguas (en adelante DAA); referente al AHEM se consultó el Fondo de Aguas (en adelante FA) y la sección de Tierras y Aguas (en adelante STA). Se examinaron los documentos de los archivos durante año y medio, en un total de 100 cajas, 250 expedientes y más de 63.000 hojas.

\footnotetext{
6 Palerm et al. 2004. Palerm, 2009. Sandré, 2011. Escobar, 2009. Fortanelli, 1997.

7 Aboites, 2000.

${ }^{8}$ Palerm, 2009:228
} 
Además de la revisión bibliográfica en temas como: el proceso de la reforma agraria relacionada al tema de la redistribución del agua y legislación de aguas del siglo XX.

Para tener un control de las múltiples variables nos guiamos con cuatro prácticas propias en la administración de recursos colectivos ${ }^{9}$ : a) actividad participativa (interacciones, demandas, expectativas), b) supresión social (poner límites a los beneficiarios para la conservación y/o frente a situaciones de escasez del recurso), c) vínculos organizativos (compartir datos sobre número de beneficiarios, tamaño del sistema, estado del recurso, comunicar discordias, demandar derechos, formar comisiones, entre otras) y, d) aminorar el conflicto.

El análisis de la información es de tipo reflexivoanalítico; nos ocupamos de algunos casos de las Juntas de Aguas donde existía variación respecto a la función del personal del Estado en el direccionamiento y participación de los usuarios como: las respuestas del personal del Estado a los reglamentos formales, los usuarios frente al manejo de un bien común y los escenarios de disputa cuando no eran precisos los turnos del agua en los reglamentos.

\section{RESULTADOS}

Los reglamentos de agua al amparo de las leyes del siglo $X X$

En el siglo XX, siendo competencia del Estado la regiduría de algunas fuentes de agua fue necesaria la emisión de un reglamento para la distribución de agua. Pero ¿qué es un reglamento? desde la ciencia política es "un ordenamiento normativo que se encuentra subordinado a la Ley que ha de ser respetada por sus destinatarios" ${ }^{10}$.

La manifestación de un reglamento a cargo del Estado posrevolucionario tiene sus antecedentes en las siguientes leyes: Ley de Aprovechamiento de aguas de jurisdicción federal de 1910, Ley Agraria de 1915, Ley federal Sobre Uso y Aprovechamiento de las Aguas Públicas Sujetas a Dominio de la Federación de 1917, Ley sobre Irrigación con Aguas Federales de 1926 y Ley de Dotaciones y Restituciones de tierra y agua de 1926. Fue a través de esta última ley, conocida también como Ley Bassols, que las autoridades buscaron unificar organizativamente a varios usuarios bajo un proceso político de reglamentación de tramos de corrientes. Estas deberían contar previamente con la declaratoria de propiedad nacional ${ }^{11}$.

Por otra parte, los variados usuarios eran aquellos que formaban parte de un grupo, como: pueblos, barrios, ejidos, cooperativas, Sociedades Cooperativas Limitadas (SCL), fábricas y compañías; y, los individuales: pequeños y grandes propietarios (ranchos y haciendas). Requirieron especificar los volúmenes de asignación de agua. Fueron dos las instituciones a las que el Poder Ejecutivo encomendó la emisión del reglamento de agua: las hidráulicas y las agrarias.

Respecto a las instituciones hidráulicas que elaboraron reglamentos de agua fueron: Secretaría de Agricultura y Fomento (en adelante, SAyF) de 1921 a 1946, entre 1926

\footnotetext{
9 Ostrom, 2000.

10 Carbonell, 2012.

11 Palerm, 2009.
}

y 1946 la Comisión Nacional de Irrigación llego a instaurar reglamentos -sin embargo éstos debían ser autorizados por la SAyF- la Secretaría de Recursos Hidráulicos (en adelante, SRH) de 1946 a 1972, la Secretaría de Agricultura y Recursos Hidráulicos (en adelante, SARH) de 1972 a 1989 y, a partir de 1989 a la fecha, la Comisión Nacional del Agua. Lo concerniente a instituciones agrarias fueron: la Comisión Nacional Agraria (en adelante CNA) de 1921 a 1934, el Departamento Agrario (en adelante DA) de 1934 a 1960, posteriormente por el Departamento de Asuntos Agrarios y Colonización (en adelante DAAyC) de 1960 a 1974, para finalmente ser función de la Secretaría de la Reforma Agraria.

“[...] los hermanos Noriega se convierten en propietarios privados de las aguas aun cuando bajo la legislación, estas aguas, debían ser propiedad federal porque por su vientre corrían una multitud de canales navegables y uno de ellos, el Canal Nacional 1960, había sido construido por la federación para facilitar el tráfico de mercancías entre la ciudad de México y su entorno agrario [...]”"12.

Así que los intereses privados estuvieron, en este caso, por encima de los federales. Habremos de manifestar que en determinados ríos, arroyos y/o manantiales existían acuerdos independientes de la Ley, espacios donde los arreglos de palabra eran admitidos por los usufructuarios del agua, sin embargo, muchos de ellos no se les reconocieron derechos de uso durante el reparto agrario, por ende, no recibieron dotación de agua ${ }^{13}$. Ante estas dificultades se recaba la siguiente información:

“[...] en el año 1977 usuarios pertenecientes a 25 familias del poblado de Totolmajac, Villa Guerrero, se quejan ante el gobernador constitucional del Estado de México porque los representantes de la Junta de Aguas del río Tequimilpa no les permiten el uso del agua en 55 hectáreas donde cosechan haba, chícharo, legumbres, granada de china y chile manzano, cuando en realidad desde antes que se construyera el canal de donde derivan sus aguas, 1944, tenían posesión [...]"14.

Además, durante el proceso de reforma agraria los propietarios de la tierra aumentaron, lo que sin duda generó trasformaciones en la forma de aprovecharla, considerando por añadidura que una misma corriente tenía más de un uso. Por las nuevas actividades comerciales y productivas desarrolladas, entendemos que los reglamentos no fueron la base o fundamento para evitar las disputas ${ }^{15}$ entre variados usuarios, pero sí se concretaron en indicar el tipo de autoridad que vigilaría su aplicación.

Procesos en la elaboración de los “nuevos" reglamentos de agua definitivos y provisionales

Durante el periodo de la reforma agraria se presentan pleitos entre diversos usuarios por el arrendamiento o

12 Archivo Histórico del Agua (en adelante AHA), Aprovechamientos Superficiales (en adelante (AS), caja 1107, expediente 15469, foja

13 Guzmán, 2006.

14 AHA, AS, 1685, 24650.

15 Gluckman (1940) Desde la disciplina de la Antropología Jurídica refiera que el concepto de conflicto son contiendas reflejadas a nivel de sistema social, por su parte, los disturbios superficiales en la vida social, dependiendo de su naturaleza, están relacionados con los términos de disputa, argumento, lucha, contención, etc. 
venta de agua que se hacía entre vecinos: el sector ejidal se quejaba por falta de agua, los pequeños propietarios denunciaban los altos cobros, inconformidad de algunos usuarios por la distribución, queja de las comunidades por la designación de autoridades bien por los ayuntamientos o bien por los representantes federales, constitución interna de juntas de agua, entre otros elementos. Dichas acciones tuvieron que ver con la adecuación de los viejos y nuevos usuarios a la normativa, pero también a la inexperiencia en temas socioculturales de los ingenieros encargados de elaborar los informes técnicos.

En principio la reglamentación de las aguas hizo surgir alteraciones en el tema del control del agua y propiedad de la tierra. Al régimen de propiedad privada, estatal, municipal y de compañías federales y privadas se unifico el régimen de propiedad social (ejidos y comunidades). Por otro lado, la promulgación del Código Agrario de 1934 establecía que las comisiones (delegaciones estatales) tenían la función de conocer los asuntos agrarios relativos a la dotación o restitución de tierras y agua. Hasta antes, todos los asuntos de la tierra y el uso del agua habían estado en manos de las instituciones federales.

La CNA al conceder agua a los ejidos también debería organizar la distribución del agua a su interior, para ello fijó cierto volumen al ejido como sujeto agrario- y, en su caso, si las tierras también eran de riego. La CNA tenía la libertad de cambiar los volúmenes de concesiones de agua a través de la dotación y dotación por accesión (tierras de riego), igualmente, intervenía en modificar el reglamento de aguas cuando se veía afectado un ejido frente a otros usuarios.

A pesar de que la CNA estaba facultada para realizar estudios y emitir el reglamento de aguas al interior de ejidos para normar, regular y ordenar los tiempos $\mathrm{y}$ cantidad de distribución, fue una constante los descontentos y oficios interpuestos por estos ante la SAyF, por la existencia de reglamentos provisionales de agua o bien por su inexacta distribución. En la toma de decisiones para definir quién debería utilizar el agua de una o varias corrientes se enviaban comisionados para que se informaran y verificaran el volumen de agua, así como los terrenos susceptibles al riego. Dicha información en muchos casos era imprecisa pues al momento de recabarla los usuarios daban información errónea.

La distribución del agua fue vaga porque las instituciones administradoras y reguladoras de tierra y agua estaban separadas; los usuarios anteriores a la reforma agraria, así como los emergidos de ella, deberían acudir con la SAyF, sin embargo, cuando un ejido tenía dificultades frente a otros propietarios, estos deberían acudir con la CNA pero se remitían a la SAyF.

Bajo estos principios normativos, los reglamentos de agua eran solicitados por diversos usuarios, quienes enviaban oficios a las autoridades correspondientes a fin de que se normaran los usos preexistentes con los emergentes. Los nuevos usuarios solicitaban garantías frente a usuarios con cierto poder, por ejemplo, los hacendados. Por otra parte, las autoridades que emitieron reglamentos de aguas establecieron asignaciones con total, parcial o falaz conocimiento del sistema hidráulico. Como ejemplo de este hecho uno de los comisionados de la SAyF dio el siguiente informe:
“[...] La mayor parte de las aguas que se asignaron a los vecinos de la cabecera de San Juan Coajomulco, municipio de Ixtlahuaca, eran dominadas por dos presas rudimentarias llamadas "la cañada" y la "bomba", pero en la actualidad la primera fue utilizada para el cultivo de maíz y, la segunda, auxiliada por una bomba, fue abandonada por el propietario de la hacienda Flor de María. Cuando se verificó el reparto de tierras se ignoró la procedencia de las aguas, las clasificaron como terrenos de riego, pero en la actualidad no pueden considerarse como tales por la sencilla razón de que no existen fuentes de aprovechamiento, y exigen los pobladores el agua de los bordos "El Establo" y "la Esperanza" [...]"16.

Ante dichas denuncias los comisionados de la federación que acudían a la inspección a los aprovechamientos, evidenciaron que en los reglamentos era impreciso el gasto de las corrientes, los cuales eran eventualmente menor a los establecidos, además las distancias existentes entre las obras de toma y los terrenos beneficiados no permitiría hacer cumplir el reglamento ${ }^{17}$. En los reglamentos también fue una constante el incumplimiento al artículo 123 de la Ley de Irrigación con Aguas Federales, este ordenaba que después de un año de vigencia de un reglamento provisional debería dictarse el definitivo; sin embargo, ocurría que las cuotas definitivas por aprovechamiento de agua eran modificadas constantemente, de igual modo se daba la integración de nuevos usuarios, esto detenía la emisión del reglamento definitivo.

Las Juntas de Agua en las legislaciones del siglo XX. Estructura y función

Los reglamentos de agua demandaron de un interventor local que vigilara su cabal cumplimiento. Es con la Ley sobre Irrigación con Aguas Federales (en adelante, LSIAF) de 1926 y su reglamento sancionado en 1930, artículo 122, que se instituye lo siguiente: “(...) la obligación de constituir una asociación de usuarios que nombre una Junta de Aguas que tenga a su cargo la aplicación del reglamento" ${ }^{18}$. La asociación de usuarios estaría integrada por uno o dos representantes de los siguientes grupos de usuarios:

I. Riego en terrenos ejidales,

II. Sistemas de riego de la Comisión Nacional de Irrigación,

III. Riego de terrenos de pequeños usuarios que formasen pueblos, rancherías, comunidades, etc.,

IV. Sociedades de usuarios,

V. Aprovechamientos para servicios públicos y domésticos,

VI. Riego en terrenos de propiedad privada y,

VII. Usos industriales y de fuerza motriz.

Las Juntas de Aguas no siempre se integraban con todos estos grupos de usuarios, tenían diferencia por la fuente de aprovechamiento común, así localizamos su presencia con uno y hasta cinco usuarios. Su constitución con diversos grupos de usuarios y usos obligaba a que cada uno de estos grupos eligiera a dos representantes

\footnotetext{
${ }^{16}$ Archivo del Registro Agrario Nacional (en adelante ARAN), Dotación de Aguas (en adelante DA), expediente 33, grupo documental 2852. ${ }^{17}$ AHA-Aguas Nacionales (en adelante AN), 350, 3726.

18 Lanz, 1982.
} 
denominándolos propietario y suplente, los que obligatoriamente deberían ser usuarios; por lo tanto, dichas personas constituían la asamblea general. En estas asambleas los representantes discutían la elección del comité directivo de la Junta de Aguas. El comité directivo era la máxima autoridad y estaba integrado por: presidente, secretario, tesorero y vocales. Estos a su vez se apoyaban de jueces o representantes de agua.

Para las funciones del comité directivo se especificaba lo siguiente (artículo 14): ordenar, vigilar, cuidar técnica y administrativamente la distribución de las aguas conforme al reglamento, llevar a cabo las sesiones reglamentarias ordinarias y extraordinarias, representar a los usuarios ante toda clase de autoridades y corporaciones similares así como atender las quejas de los usuarios y resolverlas en los siguientes casos: cuando las dificultades fueran por la aplicación del reglamento y por abusos cometidos tanto por los empleados como del personal.

En aspectos financieros: autorizar los recibos de gastos y las nóminas del personal, formar los inventarios, despachar la correspondencia, circulares, oficios, ocursos, citatorios, etc. De los asuntos relacionados con el reglamento: guardar bajo su responsabilidad los fondos entregados a la Junta de Aguas, recaudar de los usuarios las cantidades que les correspondan proporcionalmente a las dotaciones anuales a cada uno, firmar las nóminas de los empleados y hacer un corte de caja mensual, así como la relación de los gastos hechos anexando los comprobantes.

Sin embargo, como se distinguirá más adelante, las Juntas de Aguas al procurar dar un orden en el riego se encontraron con condiciones donde la norma regulaba a algunos usuarios y dejaba fuera a otros, consideraba algunas fuentes y desconocía a otras, además, los ejidos demandaban su dotación de aguas. Organizar un sistema de regadío cuyas tierras, antes de la reforma agraria, pertenecía a propietarios privados y ahora a pueblos, ejidos, hacendados, fabricas, empresas y nuevos propietarios implicó persistentes reuniones y asamblea de la Junta de Aguas al interior de los pueblos, en algunos casos unidos con propietarios privados o ayuntamiento, para el respeto de la costumbre de tandeos; en el caso de los ejidos se discutía que el volumen otorgado no era suficiente para regar la totalidad de sus tierras.

Esta situación afectaba el cabal cumplimiento de las funciones de la Junta de Aguas, ante ello siguieron un proceso de flexibilidad y ajuste a los turnos de agua. Situaciones fuera de lo marcado por la ley, lo cual les provocó sanciones por parte de la federación. Esta organización local tuvo continuidad con la Ley de Aguas de Propiedad Nacional (LAPN) de 1934, artículo 79, donde se indicó lo siguiente: "La aplicación de los reglamentos se hará mediante una Junta de Aguas elegida por los usuarios que tendrá las obligaciones y facultades que señalen las disposiciones dictada por el ejecutivo". Pero, fue hasta 1936 que se estableció su creación y se definieron sus funciones.

Por tanto, con el reglamento de la Ley de Aguas de Propiedad Federal (en adelante LAPF) de 1936 se instituyó que, en corrientes, depósitos y aprovechamientos colectivos reglamentados era obligatoria la conformación de una Junta de Aguas de todos los usuarios —regantes o no-; además, que la policía y vigilancia de tramos de corrientes debería delegarse a las Juntas de Aguas. La legislación también indicaba que se podían conformar Sociedades de Usuarios para construir y administrar obra que a su vez podrían convertirse en Juntas de Aguas.

Otro tipo de organizaciones ya establecidas, por ejemplo, la Junta Directiva de una Sociedad podía asumir el carácter de Junta de Aguas una vez reglamentados sus aprovechamientos, si de tal manera lo resolvía su Asamblea General y lo aprobaba la Secretaría ${ }^{19}$. En1972 (título cuarto, capítulo primero, art. 163, fracción VI) se indica también la obligación de los usuarios de integrar una Junta de Aguas. Sin embargo, para 1978 el apoyo legal a las Juntas de Agua es nulificado por la federación que dicta lo siguiente:

“[...] Para el 16 de abril de 1978 en la Junta de Agua del manantial Texapo, en el municipio de Texcoco, se procede a una reunión de asamblea, instada por autoridades federales y municipales, para explicar el programa de Unidades de Riego para el Desarrollo Rural motivando que, en base al artículo 77 de la LAPF, acaten la disposición de entregar la Junta de Aguas del Manantial Texapo y así proceder a denominarla Unidad de Riego del Manantial Texapo [...]”²0.

Con la Ley de Aguas Nacionales de 1992, que actualmente preside la administración del agua, no reaparecen las Juntas de Agua.

Contexto geográfico y territorial de las Juntas de Agua del Estado de México

La República Mexicana está situada en el continente americano en el hemisferio norte; parte de su territorio se encuentra en América del Norte y el resto en América Central. México se extiende entre los paralelos $14^{\circ} 32^{\prime}$ 27 ” en la desembocadura del río Suchiate y el paralelo $32^{\circ}$ 43’ 06”, que pasa por la confluencia del río Gila con el Colorado; así mismo está comprendido entre las longitudes oeste de Greenwich de $118^{\circ} 22^{\prime} 00^{\prime \prime}$ y $86^{\circ}$ $42^{\prime} 36^{\prime \prime}$ respectivamente (coordenadas extremas). El área del territorio es de 1.9 millones de kilómetros cuadrados de superficie continental. México está organizado como una República representativa, democrática y federal ${ }^{21}$. Está dividido políticamente en 31 entidades federativas y la ciudad de México, su capital.

La parte central de México presenta una zona volcánica conocida como Eje Neovolcánico Transversal, este divide a México en dos grandes regiones biogeográficas: la Neártica y la Neotropical; lo equivalente sucede en el Estado de México. La región Neártica comprende la porción centro y norte del territorio estatal, mientras que la región Neotropical abarca la parte suroeste $^{22}$. En estas dos regiones, en aspectos hidráulicos, se localizan tres cuencas hidrográficas: Pánuco, Lerma y Balsas. La prominencia de diversos climas, así como el relieve y los bosques de cedro, bosques mixtos de pinoencino y cedro-pino dan origen a numerosos manantiales, ríos permanentes y torrenciales. Durante la reforma agraria los usos para riego, fuerza motriz y uso doméstico compitieron por la apertura de nuevas tierras de cultivo,

\footnotetext{
19 Ley de Aguas de 1946, art. 90. Lanz, 1982.

20 AHA, AN, 1768, 24861.

21 Reyes, 2003.

22 Yarza De la Torre, 2003.
} 
así como la eminente urbanización y la creciente industrialización ${ }^{23}$.

La importancia social y política que representaron los recursos hídricos en el Estado de México, durante la etapa de la reforma agraria, evidenció no solo una etapa de intervención federal sobre el recurso agua, sino también una profusión de participación local frente a poderes, federales, privados y municipales, dilucidadas en organizaciones sociales denominadas Juntas de Aguas.

El total de Juntas de Aguas reportado a nivel nacional, de 1920 hasta 1980, fue de 236; de ellas, cincuenta y cinco corresponden al Estado de México representando el 23,5\% a nivel nacional. La Tabla 1 las agrupa por tipo de usos.

Tabla 1. Juntas de Agua agrupadas por usos en el Estado de México.1920 a 1980

\begin{tabular}{|c|c|}
\hline Usos del agua & $\begin{array}{c}\text { Número de Juntas } \\
\text { de Aguas }\end{array}$ \\
\hline Riego & 25 \\
\hline Riego y doméstico & 16 \\
\hline Riego y público & 2 \\
\hline Público y urbano & 1 \\
\hline Riego y fuerza motriz & 2 \\
\hline Riego, doméstico y abrevadero & 1 \\
\hline Riego, doméstico y fuerza motriz & 3 \\
\hline Riego, doméstico y público & 3 \\
\hline $\begin{array}{c}\text { Riego, doméstico, potable, } \\
\text { industrial y turístico }\end{array}$ & 1 \\
\hline $\begin{array}{c}\text { Riego, doméstico, fuerza motriz } \\
\text { e industrial }\end{array}$ & 1 \\
\hline Total & 55 \\
\hline
\end{tabular}

Fuente: AHA, AN; AHA, AS; AHA, Consultivo Técnico (en adelante $\mathrm{CT})$, diversas cajas y expedientes.

Además del uso, otra diferencia en su estructura era su presencia territorial (Figura 1); algunas estaban dentro de una demarcación municipal, en cambio otras se integraban con hasta cuatro municipios. Aclarando que su presencia era en algunas y no en todas las localidades del municipio.

Figura 1. Espacio territorial de las Juntas de Aguas del Estado de México. 1920-1980

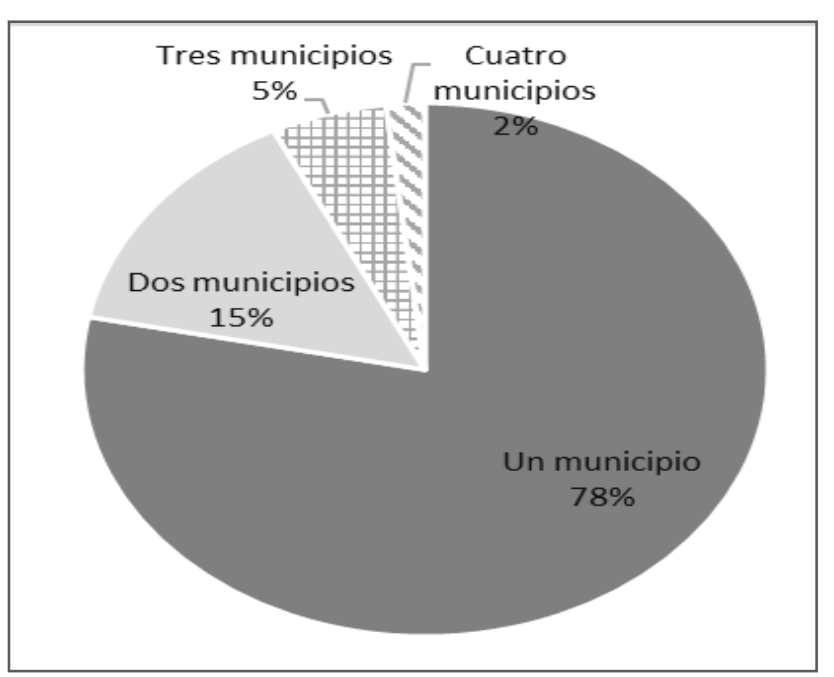

Fuente: Elaboración propia con datos de AHA, AS y AHA, AN. Diversas cajas y expedientes.

\footnotetext{
23 Demant, 1978
}

El número total de usuarios (que no representantes) de las corrientes de agua presentes en las Juntas de Agua eran: la Junta de Aguas del río Hondo de Tepotzotlán contaba con 883 usuarios, por su parte, la Junta de Aguas del Canal Hueyapan registraba a 42 usuarios con 20 hectáreas para riego de terrenos de pequeña propiedad y ejidal. El promedio de hectáreas por usuarios para el caso de pueblos y ejidos comprendía entre $1 / 4$ a 21/4. Respecto a las horas de riego marcadas en el reglamento, estas dependían de la cantidad de hectáreas, así los pueblos y ejidos recibían en promedio desde 166 hasta solo 5 horas.

Por otra parte, de acuerdo con el tipo de propiedad encontramos dificultades entre los grandes usuarios (haciendas, ranchos, fraccionamientos, propiedad privada) con los medianos y pequeños propietarios (pueblos, ejidos, barrios); pero también entre los medianos y pequeños propietarios. La Tabla 2 ejemplifica las más recurrentes acciones de quejas presentes en las Juntas.

Son frecuentes en cada cambio de mesa directiva estos asuntos, destaca el hecho siguiente: las autoridades federales tenían el conocimiento de las disputas por la distribución del agua desde el discurso de comisionados, usuarios con propiedad social y/o propiedad privada, autoridades municipales y estatales. Los canales de comunicación eran por medio de correo postal o de manera directa pero las resoluciones o atención a estos eran tardías.

Actividad participativa, interacciones, demandas $y$ expectativas de las Juntas de Aguas. Algunos casos

Los vínculos de las Juntas de Aguas con usuarios colectivos y privados, autoridades federales, estatales y municipales dependían de la diversidad y cantidad de usuarios; en este sentido, el interés por las relaciones sociales surgidas se explica por: la afectación de los volúmenes de agua anteriores a la reglamentación de fuentes de agua, los intentos de modificación al reglamento, la elección de representantes, los abusos de grupos en el poder como hacendados, rancheros, ayuntamientos y empresarios; y la aplicación de sanciones a infractores del reglamento.

Para esclarecer estas acciones inciertas presentes al interior de las Juntas de Aguas señalaremos que, las autoridades federales mantuvieron relaciones sociales directamente con los pueblos. El siguiente informe del comisionado para el caso de la Junta de Aguas del Arroyo Lanzarote es un ejemplo de este pronunciamiento:

“[...] es casi unánime la opinión que se debe cambiar el actual reglamento de aguas por otro más equitativo, propuesto por la SRH, por lo que llevé a cabo una asamblea con el pueblo de Huilango para obtener su opinión y piden que se cambie el tandeo en sentido inverso; como no es posible hacerlo, pues se actuaría con parcialidad, he procurado respetar la costumbre que tienen desde hace 200 años de efectuar rotaciones. No se le ha quitado a nadie el tiempo que les corresponde, el pueblo de Huilango dispone de 9 horas, pero pierde tres de ellas por la demora en que tarda en llegar el agua, con el retorno de turnos que propongo no tendrían perdida y recuperaría sus horas, pues estaría tomándola directamente del caño y de manera inmediata del pueblo que les antecede [...]”24.

${ }^{24}$ AHA, AN, 3716, 82-86. Caño refiere a un canal distribuidor de agua de pequeñas dimensiones sin revestimiento de ningún tipo. 
Tabla 2. Concentrado de inconformidades entre actores sociales, empresariales y políticas presentes en las Juntas de Aguas

\begin{tabular}{|c|c|c|c|}
\hline Nombre & Quejoso-inculpado & Quejas & Solución \\
\hline $\begin{array}{l}\text { Junta de aguas } \\
\text { río Xalapango, } \\
\text { Los Reyes la } \\
\text { paz }\end{array}$ & $\begin{array}{l}\text { Usuarios-Junta de } \\
\text { Aguas }\end{array}$ & $\begin{array}{l}\text { Imposición de cuotas para reconstrucción de presa y } \\
\text { disminución de dos horas diarias de riego }\end{array}$ & $\begin{array}{c}\text { Intervención de autoridad federal para que } \\
\text { la Junta de Aguas presente el proyecto } \\
\text { para ser sancionado; mientras tanto se le } \\
\text { indica abstenerse de realizar cobros así } \\
\text { como disminuir horas de riego }\end{array}$ \\
\hline \multirow{5}{*}{$\begin{array}{l}\text { Junta de aguas } \\
\text { del rí́ } \\
\text { Polotitlán }\end{array}$} & $\begin{array}{l}\text { Junta de Aguas- } \\
\text { síndico de } \\
\text { ayuntamiento }\end{array}$ & $\begin{array}{l}\text { El síndico y su guardia empistolada amenazan a } \\
\text { usuarios y zanjero por la forma en que se realiza el } \\
\text { tandeo de agua }\end{array}$ & $\begin{array}{c}\text { El comisionado acude para manifestar a la } \\
\text { autoridad del municipio se abstenga de } \\
\text { participar en funciones de la Junta de } \\
\text { Aguas } \\
\end{array}$ \\
\hline & $\begin{array}{l}\text { Ejidatarios-Junta de } \\
\text { Aguas }\end{array}$ & $\begin{array}{l}\text { Inconformes por los permisos que se otorgan para riego } \\
\text { de tierras que no están comprendidas con derecho }\end{array}$ & Se renueva la Junta de Aguas \\
\hline & $\begin{array}{l}\text { Junta de Aguas- } \\
\text { Arrendatarios }\end{array}$ & Robo de agua & $\begin{array}{l}\text { Imposición de multa y reorganización de } \\
\text { los tiempos de distribución del agua }\end{array}$ \\
\hline & $\begin{array}{l}\text { Pueblo-Junta de } \\
\text { Aguas }\end{array}$ & $\begin{array}{l}\text { La distribución global del tandeo al pueblo provocó } \\
\text { pugnas con sus barrios }\end{array}$ & $\begin{array}{c}\text { Se modifica la reglamentación y se } \\
\text { incluye en la distribución a los barrios. Se } \\
\text { elabora la distribución por parcelas } \\
\text { individuales o por límites de barrios }\end{array}$ \\
\hline & $\begin{array}{l}\text { Presidente de Junta de } \\
\text { Aguas-Tesorero } \\
\\
\text { Junta de Aguas- } \\
\text { representantes } \\
\end{array}$ & $\begin{array}{l}\text { Disputa entre presidente y tesorero por no rendición de } \\
\text { cuentas. } \\
\text { Aprovechan los representantes para resguardar el dinero } \\
\text { que algunos usuarios les han entregado }\end{array}$ & $\begin{array}{c}\text { Asamblea comunitaria para el desahogo } \\
\text { de pruebas y renuncia del tesorero. } \\
\text { Obligan a los representantes a entregar el } \\
\text { dinero y resguardarlo en la casa comercial } \\
\text { de un usuario que forma parte de la mesa } \\
\text { directiva. } \\
\end{array}$ \\
\hline \multirow{2}{*}{$\begin{array}{l}\text { Junta de Aguas } \\
\text { del río } \\
\text { Cuautitlán }\end{array}$} & $\begin{array}{l}\text { Pueblo de Santa } \\
\text { Bárbara-Junta de } \\
\text { Agua }\end{array}$ & $\begin{array}{l}\text { Inconformidad por descontar trece horas y media de } \\
\text { riego para entregárselas a un rancho. Las tierras del } \\
\text { rancho no tienen el carácter de riego }\end{array}$ & $\begin{array}{c}\text { Se acuerda disminuir las horas de riego al } \\
\text { rancho en proporción del } 50 \% \text { y deberá } \\
\text { tomar el agua al finalizar todos los } \\
\text { usuarios, y no antes como lo venía } \\
\text { haciendo }\end{array}$ \\
\hline & $\begin{array}{r}\text { Junta de Aguas- } \\
\text { Fraccionamiento } \\
\text { Nueva Ixtapa S.A. } \\
\end{array}$ & Los fraccionamientos urbanos se niegan a pagar el agua & $\begin{array}{c}\text { Se solicitan dos policías de la ciudad de } \\
\text { Toluca para que vigilen el canal e impidan } \\
\text { tomar agua a los usuarios que se niegan a } \\
\text { pagar } \\
\end{array}$ \\
\hline \multirow{4}{*}{$\begin{array}{l}\text { Junta de Aguas } \\
\text { río Tequimilpan } \\
\text { Ixtapan de la } \\
\text { Sal }\end{array}$} & $\begin{array}{l}\text { Usuarios-Junta de } \\
\text { Aguas }\end{array}$ & $\begin{array}{l}\text { Mencionan que disfrutaron del agua desde } 1942 \text { hasta } \\
1959 \text { de forma pacífica. Atribuyen al nuevo reglamento } \\
\text { que les perjudicó gravemente en sus volúmenes } \\
\text { establecidos, además se ser incongruentes }{ }^{26} \text {. Los } \\
\text { hoteleros desperdician el agua (jardines) que no les } \\
\text { corresponde. }\end{array}$ & $\begin{array}{l}\text { Piden se modifique el reglamento, al no } \\
\text { recibir respuesta de la Junta de Aguas } \\
\text { remiten su queja al Presidente de la } \\
\text { República (Luis Echeverría) }\end{array}$ \\
\hline & $\begin{array}{c}\text { Pueblo de } \\
\text { Totolmajac-Junta de } \\
\text { Aguas } \\
\end{array}$ & $\begin{array}{l}\mathrm{Al} \text { aplicarse el nuevo reglamento de las aguas se } \\
\text { benefició a grupos influyentes }\end{array}$ & Se hace caso omiso \\
\hline & $\begin{array}{l}\text { Pueblo de Ixtacalco- } \\
\text { Secretaría de } \\
\text { Recursos Hidráulico }\end{array}$ & $\begin{array}{l}\text { Manifiestan que el poblado de Melchor Ocampo eligió } \\
\text { un distribuidor de aguas y piden se cambie por uno } \\
\text { originario del pueblo de Ixtacalco }\end{array}$ & $\begin{array}{l}\text { Se comisiona a un representante para que } \\
\text { convoque a los usuarios para la nueva } \\
\text { elección de representantes }\end{array}$ \\
\hline & $\begin{array}{l}\text { Usuarios- rancheros y } \\
\text { hacendados }\end{array}$ & $\begin{array}{c}\text { Los hacendados y dueños de ranchos imponen su } \\
\text { planilla para elegir representantes, afectando a los } \\
\text { pueblos }\end{array}$ & $\begin{array}{l}\text { Se realizan elecciones con presencia de } \\
\text { autoridades federales negando la presencia } \\
\text { de las municipales. }\end{array}$ \\
\hline $\begin{array}{l}\text { Junta de Aguas } \\
\text { de Cuautitlán }\end{array}$ & $\begin{array}{l}\text { Junta de Aguas- } \\
\text { Secretaría de } \\
\text { Agricultura y } \\
\text { Fomento }\end{array}$ & $\begin{array}{l}\text { Se quejaron usuarios de varios pueblos porque la Junta } \\
\text { de Aguas los sancionó con suspensión de servicio de } \\
\text { riego por un año por infracción al reglamento. La } \\
\text { dirección de aguas de la SAyF pide se les restituyan sus } \\
\text { derechos. }\end{array}$ & $\begin{array}{l}\text { Todos los integrantes de la Junta de Aguas } \\
\text { renunciaron porque la solicitud de la } \\
\text { SAyF les restaba funciones }\end{array}$ \\
\hline $\begin{array}{l}\text { Junta de Aguas } \\
\text { del canal } \\
\text { Hueyapan } \\
\text { (Texcoco) }\end{array}$ & $\begin{array}{l}\text { Usuarios-Secretaría } \\
\text { de Recursos } \\
\text { Hidráulicos }\end{array}$ & $\begin{array}{l}\text { Los usuarios se niegan a aceptar que los dueños de } \\
\text { ranchos sean electos en cargos directivos; el argumento } \\
\text { es que son de ideas contrarias a la de los campesinos y } \\
\text { porque perjudican sus intereses }\end{array}$ & $\begin{array}{c}\text { Se realiza el cambio total de la mesa } \\
\text { directiva }\end{array}$ \\
\hline
\end{tabular}

Fuente: AHA, AN, 1036, 13550, 179 (Ixtapan de la Sal). AHA, AN, 1891, 26594, 2, 161 (Cuautilán Izcalli). AHA, CT, 200,1678, 38 (Texcoco). Archivo Histórico del Estado de México (en adelante (AHEM), Irrigación, 8, 2, 1953.

25 AHA, AN, 346, 3716, 13.

${ }^{26}$ Al poblado de Totolmajac con 300 hectáreas de le fijan 99,2 litros por segundo (lps) al pueblo de Ixtapan Viejo con 150 hectáreas se le asignan los mismos litros y a la zona hotelera de Ixtapan con 273 hectáreas (50 de ellas para viveros y el resto para jardines) se le asignan 135 lps. AHA, AS, 1329, 18092, 78. 
El interés por disminuir las disputas, motivados principalmente por la afectación de algunos usuarios, deviene de las quejas presentadas por estos en lo referente al tandeo y reglamento. Pero también porque en los reglamentos de agua no se consideró que el volumen, para el caso de las presas, dependía de las precipitaciones pluviales. Para 1946 el presidente de la Junta de Aguas informa a la SAyF:

"[...] que en este año se dispone de una reducida cantidad de agua en las presas de Santa Elena y Shimojay, así como del río Coscomate para dotar a los ejidos y pequeños propietarios, en virtud de la escasez de lluvias de 1945. La junta somete a consideración de la dirección de aguas un proyecto de distribución para esta situación de escasez, que una vez aprobado se discutiría con cada uno de los representantes de los pueblos para proceder a las siembras $[\ldots . ., 27$

Encontramos ciertas imprecisiones en los informes de los comisionados al momento de resolver dificultades de carácter interno. Por una parte proponían, para que el reglamento se cumpliera, que un juez de aguas manejara las compuertas de la corriente, apoyada de los representantes de cada pueblo; no obstante, en otros informes comentaban que estos dificultaban y afectaban la distribución de aguas. Este último hecho es transcendental, ya que nos muestra cómo los comisionados, además de manifestar su desaprobación a autoridades tradicionales del agua de larga data, tratan de solucionar las disputas por el agua mediante la supresión. En un informe oficial se encuentra lo siguiente:

“[...] el pueblo de Huexotla realizó una asamblea para nombrar un juez por este pueblo y otro por el de Tequexquinahuac, ambos usuarios de los manantiales de Quiloapan y Atzumpa y otros existentes. Los jueces de agua desempeñan el trabajo correspondiente a canaleros o repartidores y no como presidentes o repartidores de la distribución de las aguas. Esto en la práctica según he podido observar da por resultado que siendo de hecho juez de aguas un canalero pagado por el pueblo no se reconozca su autoridad, la autoridad que reconocen es comisariado civil ya que éste nombra las guardias que gratuitamente 0 por obligación vigilan el reparto de las aguas. Estas anomalías pueden corregirse quitando toda injerencia al comisariado civil, nombrándose un presidente, cesando así el conflicto creado con motivo del reparto de esas aguas, igual caso se encuentran juntas de aguas por esa región que tienen jueces en lugar de presidentes [... $]^{\text {228 }}$.

En este sentido, la Junta de Aguas era la institución social que incorporaba figuras organizativas históricas como el juez de aguas. En otros casos se crea una nueva figura. La siguiente petición del presidente de la Junta de Aguas de Papalotla a la SRH es un ejemplo de lo mencionado:

“[...] considero necesario, para evitar el robo de agua, poner un delegado de aguas en la parte alta para que cuide el cumplimiento del reglamento, entretanto se ejecutan las obras de construcción de una caja de agua que apartará las aguas del rio con las del canal. Pido su autorización para nombrar a un delegado para que los usuarios de la Junta de Aguas de Hueyapan no sigan cometiendo fraudes” ${ }^{29}$.

\footnotetext{
${ }^{27}$ AHA, AN, 350, 3723, 4. AHA, AS, 347, 3716.

${ }^{28}$ AHA, AS, 2596, 36402.

${ }^{29}$ AHEM, Aguas, 20, 4, 1942.
}

Estas organizaciones al ser constituidas con numerosos usos atienden a problemáticas territoriales, lo cual es meritorio en el sentido de no desarticular física y geográficamente el recurso hídrico. Al ser compartida una corriente por varios usuarios, discurrían los intereses políticos y económicos. Este hecho provocaba la subdivisión de las Juntas, entre dos o hasta en cuatro, como el caso de las siguientes que se fraccionaron: La Junta de Huexotla (Junta de Aguas de Tequesquinahuac y Junta de aguas del pueblo de Huexotla); y, Junta de Aguas del Rio Cuautitlán (Asociación de usuarios de Teoloyucan, Junta de Aguas de Tepotzotlán, Junta de aguas de Teoloyucan y Junta de Aguas del Canal Cuamatla). En otro espacio de riego, al norte de la capital del Estado de México, los usuarios de Acuescomac informan lo siguiente al comisionado:

"[...] existe un acuerdo interno entre los ejidatarios y pequeños propietarios de alternarse el riego, así que, tanto ejidatarios como pequeños propietarios riegan en el mismo tiempo para cultivo de alfalfa. Con visto bueno del presidente de la junta de aguas [...]"30

Además, la emergencia de autoridades históricas en el reparto de agua, sobre todo de comunidades y pueblos, rompía con lo establecido en el reglamento. Sin ánimo de generalizar las funciones de las Juntas de Aguas presentamos los influjos entre lo legal y el pragmatismo. No deja de ser imperante que, a pesar de los cambios legales en el tema de la tierra, lo cual incrementó la superficie de riego y los usos, predomine la continuidad de prácticas sociales organizativas establecidas en antiguos sistemas de regadío.

Supresión social. Límites a los beneficiarios para la conservación y/o frente a situaciones de escasez del recurso o simulaciones

De manera formal competía a los representantes de las instituciones federales definir quiénes formaban parte de la Junta de Aguas y quiénes no, también permitían y autorizaban que algunos usuarios se separaran de la Junta de Aguas. Generalmente a estos usuarios se le otorgaba una asignación especial y comúnmente aplicaba a los ranchos.

Para el caso del comité directivo de las Juntas de Aguas la restricción a algunos usuarios al acceso del agua estaba marcada por derechos históricos, o como parte del registro de usuarios en los títulos de concesión del siglo XX. En esta sección existieron contrastes notables marcados por un manejo común del recurso agua. Los pueblos y ejidos generaron un sentido de pertenencia hacia el agua, evidenciado en las prácticas habituales de faenas comunitarias para la limpia de canales de riego. Por su parte las haciendas y ranchos trataron de ajustarse a los reglamentos formales de agua.

Las Juntas de Agua aplicaban sanciones y suprimían temporalmente derechos de acceso al agua a los usuarios que no cumpliesen con la labor de limpia y/o cooperación para el mantenimiento o rehabilitación de obras. En el caso de las fábricas se les multaba con cantidades que muchas veces consideraban elevadas y enviaban de inmediato su queja a las instituciones federales. Las

${ }^{30}$ AHA, AS, 426, 7768 
haciendas y los ranchos enviaban a peones a realizar estas labores, pero eran prohibidos sus tandeos de agua frecuentemente porque alteraban la red hidráulica con la apertura de nuevos canales de riego, derivaciones, almacenamientos de agua, o bien porque ampliaban sus tierras de cultivo sin informar a la Junta de Aguas.

Las funciones de algunas Juntas de Aguas no se inmovilizan a lo indicado en los reglamentos, por el contrario, involucran para el cumplimiento de la parte administrativa formal, las experiencias comunitarias en el manejo de bienes comunes.

Vínculos organizativos para disminuir costos económicos, defender el recurso y/o reducir el conflicto

Las medidas tomadas por algunas Juntas de Aguas respecto a la ordenanza de un estado financiero fue la primera causa de conflicto con las instituciones federales. Suponemos que la historia de manejo de bienes comunes por parte de los usuarios, pertenecientes a pueblos y ejidos, al denotar que el agua continuaría como un bien natural y no económico los facultó para no adquirir el agua bajo un modelo lucrativo y especulativo. En 1949 informa el comisionado lo siguiente:

“[...] que no hay egresos ni egresos de la junta de Aguas Muchachos Quemados y otros, porque no es costumbre el cobro del agua, además los trabajos de limpia de canal se hacen por faenas y cuando existe un problema como el de deterioró de la red, se cooperan todos los usuarios. Informa que la distribución de agua se hace de forma irregular pues no existen canaleros, ni vigilantes siendo los propios representantes de los diversos grupos encargados de repartir, vigilar que los suyos reciban dotación, en esa forma no es posible observar el tandeo, lo que resulta que unos sean favorecidos y otros desfavorecidos. Finalmente, se les imponen multas a usuarios que dan órdenes y disposiciones de distribución de agua, sin ser autoridades [...]"31.

Debemos registrar que en el ímpetu de las autoridades federales por aplicar los reglamentos nulificaron las habilidades de los usuarios, en conjunto con sus autoridades locales, para operar, y en algunos casos, construir y rehabilitar obra en sistemas tanto simples como complejos de agua; a pesar de evidenciar que era posible administrar y controlar las corrientes sin que el aspecto financiero interrumpiera o limitara el acceso del agua, se ejerció una coerción constante a las Juntas de Agua para apegarse a un estado financiero. El caso de la Junta de Aguas del Canal Hueyapan, Texcoco, el presidente informa al comisionado de la SRH que no se sujetan al presupuesto porque no tienen más gastos que el pequeño sueldo o gratificación dado al distribuidor o canalero, que tienen funciones siete años aproximadamente y no hay motivo de queja contra él ${ }^{32}$.

Transformaciones del territorio estatal, deterioro y continuidad de las Juntas de Agua

En el Estado de México las Juntas de Agua presentes en el AHA manifiestan un sistema organizativo de aprovechamientos colectivos de agua histórica, el caso de las Juntas de Aguas de Polotitlán (1601), Junta de Aguas de Manantiales de San Juan Teotihuacán (1680), y Junta de Aguas del río dos quintas partes del río Tintojo (1882). En el siglo XX, las disposiciones reglamentarias inician en

\footnotetext{
31 AHA, AS, 2203, 32628.

32 AHA, AS, 2393, 34067.
}

el año 1921, mostrando algunas Juntas de Aguas de dos hasta cinco reglamentos, estos culminan en el año 1986 con la Junta de Aguas del Manantial Atexcac, Texcoco.

Las condiciones productivas, demográficas, industriales y políticas del Estado de México a partir de 1940 habrían de tener repercusiones socio-territoriales en la distribución del agua. Por una parte, porque algunas Juntas de Agua quedaron circunscritas a la política hídrica de Distritos de Riego (DR), por ejemplo, la Junta de Aguas de Aculco y la Junta de Aguas de Polotitlán fueron integradas al DR 096 y Junta de Aguas del río Coscomate o presa Santa Elena constituida al DR 073. Otro factor fue la transferencia de agua de la cuenca Lerma a la cuenca del Valle de México, lo que sin duda produjo un ecocidio, promoviendo en las Juntas de Agua de Temoaya una escasez hídrica, fundamentada en la extracción de agua subterránea. Este hecho ha promovido el conflicto por el agua de los manantiales con el municipio de Otzolotepec el cual busca afanosamente la provisión doméstica de su creciente población.

\section{CONCLUSIONES}

El estudio de las Juntas de Aguas en conjunción con la propiedad de la tierra, durante el proceso de la reforma agraria, refleja que la regulación de las corrientes y su distribución, en la mayor parte del siglo XX, está relacionada con los reglamentos formales e informales o, mejor dicho, con aspectos históricos de manejo de agua. La interpretación y aplicación de reglamentos formales, en las corrientes donde operaron las Juntas de Agua, dio muestra de estructuras organizativas de base que reconocieron, defendieron y continuaron con la protección vía el ejercicio de accionar colectivo.

Al mismo tiempo, las Juntas de Aguas presentaron continuidad de relaciones conflictivas porque se instituyeron en espacios donde ya existían acuerdos de distribución de agua; y a estos se incluyeron nuevos usuarios como los ejidatarios, barrios, pueblos y fraccionamientos. La creación de los ejidos y la dotación del volumen de agua sin considerar la disponibilidad hídrica de los territorios conllevaron a las autoridades federales a la modificación constante de los reglamentos. Por otra parte, en la década de los ochenta se da un ultimátum legal a una historia de espacios de concertación social a nivel local, promovida por el cambio de Juntas de Aguas a Unidades de Riego. Parece que dicho hecho deviene de la inexperiencia de las instituciones federales para adecuarse a los requerimientos de índole económicos (cuotas), legales (incremento de ejidos), sociales (preorganizaciones) y técnicos (flexibilidad en los tandeos).

Por último, la articulación de diversos tipos de usos afirmada, vía la Junta de Aguas, mantuvo relaciones conflictivas con autoridades municipales o privadas porque los reglamentos provisionales, aún los definitorios, eran equívocos. Los ejidatarios, como nuevos actores dentro de la política mexicana, mostraron formas distintas de relación con los anteriores propietarios de la tierra y agua, de manera que se involucraron en la regulación adquiriendo un empoderamiento in situ, lo cual ocasionó tensiones en sus relaciones con el poder federal y con los anteriores poderes locales de ayuntamientos, hacendados e industriales, y aún entre ellos. 


\section{ARCHIVOS (SigLAS) Y BIBLIOGRAFÍA}

Archivo Histórico del Agua (AHA). México, D. F. Fondos: Aprovechamientos Superficiales (AS) Aguas Nacionales (AN) y Consultivo Técnico (CT).

Archivo del Registro Agrario Nacional (ARAN). Toluca, Estado de México. Dotación de Aguas.

Archivo Histórico del Estado de México (AHEM). Toluca, Estado de México Fondos Aguas, Expediente Tierra y Aguas.

Aboites, L. 2000: La decadencia del agua de la nación. Estudio sobre desigualdad social y cambio político en México. Segunda mitad del siglo XX. México, El Colegio de México.

Aboites Aguilar, L., y Estrada, T. V. 2004: Del agua municipal al agua nacional. Materiales para una historia de los municipios en México 1901-1945. México, Centro de Investigación y Estudios Superiores en Antropología Social, Colegio de México.

Aguirre González, N.A., Montes, H. R. 2013: "Juntas de Aguas del río Tejalpa y sus afluentes”, en Palerm, V. J., Martínez, T. S. (eds.): Antología sobre riego, Biblioteca Básica de Agricultura, Texcoco, México, Colegio de posgraduados, 275-300.

Boelens, R. 2003: "Derechos de agua, gestión indígena y legislación nacional. La Lucha Indígena por el Agua y las Políticas Culturales de la Participación”, Boletín del Archivo Histórico del Agua Nueva Época, Archivo Histórico del Agua, 8, 5-19.

Castillo Nonato, J. 2015: "El proceso de transferencia a partir de la Ley de Aguas de 1992 en México: el caso de la Junta de Aguas del río Temoaya y su transformación en Unidades de Riego (1934-2013)”, Agua y territorio, 5, 99-110, https://dx.doi.org/10.17561/at.v0i5.2537

Lanz Cárdenas, J. T. 1982: Legislación de aguas en México. Estudio Histórico y Legislativo. De 1521 a 1981. Vol. 1, México, Consejo Editorial del Gobierno del Estado de Tabasco.

Carbonell. M. (Coords.) 2014: Diccionario Jurídico Básico. México, Instituto de Investigaciones Jurídicas.

Castañeda García, R. 2005: "El Estado posrevolucionario visto desde su intervención en la gestión del agua de pequeños sistemas de riego, 1920-1940”, en Durán, J. M., Sánchez, M. y Escobar O. A. (Coords.): El agua en la historia de México. Balance y perspectiva. Zamora, El Colegio de Michoacán.

Comisión Nacional de la Biodiversidad (Conabio) 2016: Geoportal del Sistema Nacional de Información, en http://www.conabio.gob.mx/informacion/gis/ Consulta realizada el 15 de julio de 2016.

Demant, A. 1978: "Características del Eje Neovolcánico Transmexicano y sus problemas de interpretación”, Revista del Instituto de Geología, 2(2), 172-187.

Escobar, O.; Ávila Q. A.: Gómez S. y Sánchez, R. M. (Coords.) 2009: Negociaciones, acuerdos y conflictos en México, siglos XIX y XX. Agua y tierra. México, El Colegio de Michoacán, Centro de Investigaciones y Estudios Superiores en Antropología Social, Universidad Autónoma de Aguascalientes.

Fabila. M. (comp.) 2005: Cinco Siglos de Legislación Agraria (1493-1940). México, Secretaría de la Reforma Agraria.

Fortanelli, M. 1997: “Pequeña agricultura de regadío”, en Martínez, T. y Palerm, J. (eds.) Antología sobre pequeño riego. México, Colegio de Postgraduados. 323-366.

Gluckman, M.1940: "Analysis of a social situation in modern Zululand", Rhodes-Livingstone Paper, 28, 1-27, https://doi.org/10.1080/02561751.1940.9676112
Glick, T. 1988: Regadío y sociedad en la Valencia medieval. Valencia, Del Cenia al Segura.

Guzmán R. N.B. 2006: "el rodeo, un caso de unidad de riego autogestionada”, Boletín del Archivo Histórico del Agua, Nueva Época, 11, 48-55.

Lanz, C. J. 1982: Legislación de aguas en México. Estudio históricolegislativo de 1521-1981, IV tomos. México, Consejo Editorial del Gobierno del estado de Tabasco.

Mendieta, N. L. 1978: El problema agrario de México, desde su origen hasta la época actual. México, Centro de Investigación y Estudios Superiores en Antropología Social.

Ostrom, E. 2000: El gobierno de los bienes comunes. La evolución de las instituciones de acción colectiva. México, Universidad Autónoma del Estado de México, Centro Regional de Investigaciones Multidisciplinarias, Centro Fondo de Cultura Económica.

Palerm Viqueira, J. y Martínez Saldaña, T. (eds.) 2009: Aventuras con el Agua. México, Consejo Nacional de Ciencia y Tecnología.

Palerm Viqueira. J. y Martínez Saldaña, T. (eds.) 2013: Antología sobre riego: Instituciones para la gestión del agua: vernáculas, alegales e informales. México, Colegio de Postgraduados.

Palerm Viqueira, J.; Sandre, I.; Rodríguez H. B. y Duana N. (eds.) 2004: Catálogo de Reglamentos de Agua en México, Siglo XX. Archivo Histórico del Agua Centro de Investigación y Estudios Superiores en Antropología Social, Comisión Nacional del Agua.

Reyes, P. 2003: Explorando la Geografía de México. México, Nuevo México.

Rodríguez H. B.; Rosas V. R. y Ruiz, R. H. 2010: "Las Juntas de Aguas: Búsqueda de un Modelo de Administración y Operación de Sistemas de Riego", Ra Ximhai, $\quad 6, \quad 2, \quad$ 295-301, https://doi.org/10.35197/rx.06.02.2010.10.br

Sandré Osorio, I. 2008: Conflicto y gestión del agua. Documentos para el estudio de las Juntas de Aguas en el Valle de México, 1920-1950. México, Centro de Investigaciones y Estudios Superiores en Antropología Social, Comisión Nacional del Agua y Archivo Histórico del Agua.

Sandré, Osorio. I. y Sánchez, M. (eds.) 2011: El eslabón perdido. Acuerdos, convenios, reglamentos y leyes locales de agua en México, 1593-1935. México, Centro de Investigación y Estudios Superiores en Antropología Social.

Stone, I. 1984: Canal irrigation in British India. New York, Cambrige University.

Tamayo, J. 1958: El aprovechamiento del agua y del suelo en México. México, Secretaría de Recursos Hidráulicos, Jefatura de operación de Distritos de Riego.

Torregrosa, M. L. 2009: Agua y riego. Desregularización de la agricultura en México. México, Flacso.

Tortolero, A. 2008: Notarios y agricultores: crecimiento y atraso en el campo mexicano, 1780-1920: propiedad, crédito, irrigación y conflictos sociales en el agro mexicano. México, Siglo XXI, Universidad Autónoma Metropolitana Iztapalapa.

Valladares de la Cruz, L. 2003: Cuando el agua se esfumo. Cambios y continuidades en los usos sociales del agua en Morelos. 1880-1940. México, Universidad Autónoma del Estado de México.

Yarza de De la Torre, E. 2003: "Los volcanes del Sistema Volcánico Transversal”, Investigaciones Geográficas, Boletín del Instituto de Geografía, 50, 220-234. 